\title{
Letter
}

Dermatology

Published online: August 27, 2018

Dermatology 2018;234:232-233

DOI: $10.1159 / 000491547$

\section{Hurley III Hidradenitis Suppurativa Has an Aggressive Disease Course}

\author{
Annika M.J.D. Vanlaerhoven Christine B. Ardon \\ Kelsey R. van Straalen Allard R.J.V. Vossen Errol P. Prens \\ Hessel $\mathrm{H}$. van der Zee \\ Department of Dermatology, Erasmus University Medical \\ Centre, Rotterdam, The Netherlands
}

Keywords

Acne inversa $\cdot$ Clinical course $\cdot$ Progression

Hidradenitis suppurativa (HS) is a chronic, autoinflammatory skin disease [1]. HS severity can be classified into three stages according to Hurley: Hurley I (45.5\% of the patients), Hurley II (41.5\% of the patients), and Hurley III (13.0\% of the patients) (Table 1) $[2,3]$. If progression to a more severe Hurley stage takes place, it is considered irreversible. Even though it is of high clinical relevance, there is currently no information available on the time course of disease progression through these stages. Therefore, we retrospectively studied the disease progression rate.

In 2017, all consecutive HS patients were asked to fill out a supervised questionnaire regarding their disease progression, with the current Hurley stage classified by a dermatologist. Photographs, validated for self-assessing the Hurley stage [4], with an oral explanation, were used to support patients in recalling the time path of disease progression to each consecutive Hurley stage. A two-sided alpha of $<0.05$ was considered to be statistically significant. This survey was approved by the medical ethics committee of the Erasmus Medical Centre.

A total of 225 patients completed the questionnaire: 77 (34.2\%) Hurley I, 98 (43.6\%) Hurley II, and 50 (22.2\%) Hurley III patients.
The median disease duration of Hurley I patients was 9 years (IQR 4-18). Both Hurley II and Hurley III patients developed their current Hurley stage 6 years ago $(p=0.633)$ and the two groups reached their current stage in a median time period of 6 and 5 years (IQR 3-12 and $2-12$, respectively). However, the progression from Hurley I to Hurley II was significantly shorter in current Hurley III patients with a median time period of 3 years (IQR 1-5). Moreover, the progression from Hurley II to Hurley III was even faster at 2 years (IQR 1-6). The progression time from Hurley I to Hurley II in current Hurley II patients was significantly shorter compared with the disease duration in Hurley I patients $(p=0.038)$. The time course of disease progression with respect to severity is visualized in Figure 1.

To our knowledge, this study is the most detailed report on disease progression rates in HS. Previously, Kromann et al. [5] studied long-term follow-up of $121 \mathrm{HS}$ patients and reported a questionnaire-based remission in 39\%, improvement in 32\%, unchanged severity in $21 \%$, and worsening in $9 \%$ of patients after an average period of 22 years. In addition, von der Werth et al. [6] reported that HS patients reached their maximum disease activity after a mean disease duration of 6.4 years. However, disease severity was not specified. Our results regarding time to maximum disease are comparable. The fact that stage I and II patients have stationary

Table 1. Hurley severity staging

Hurley stage

I Abscess formation, single or multiple, without sinus tracts and cicatrization

II Recurrent abscesses with tract formation and cicatrization, single or multiple, widely separated lesions

III Diffuse or near-diffuse involvement, or multiple interconnected tracts and abscesses across the entire area

Fig. 1. Disease progression of hidradenitis

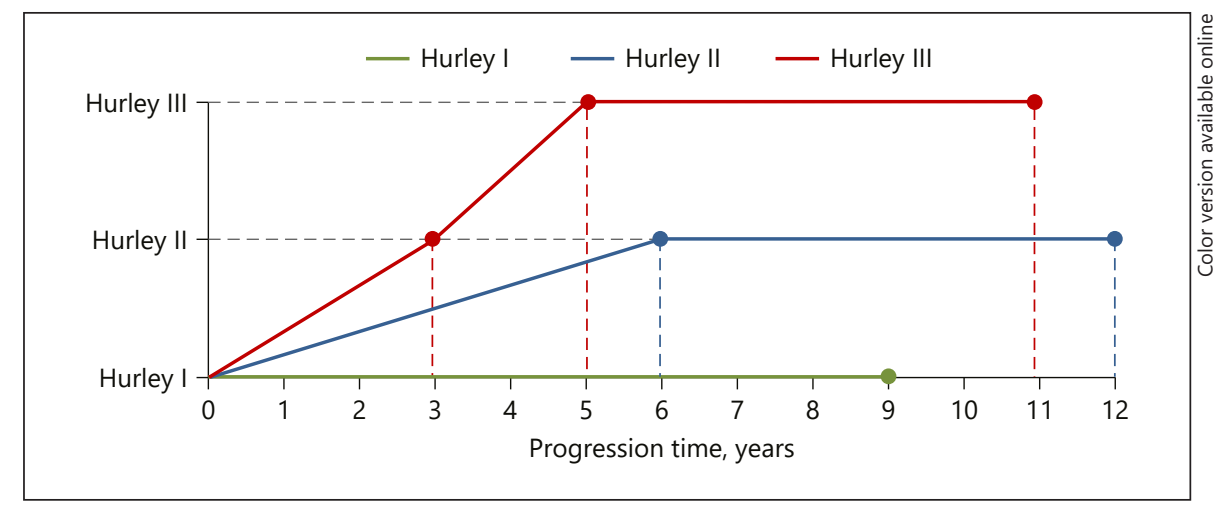
suppurativa patients.

Annika M.J.D. Vanlaerhoven

Department of Dermatology, Erasmus Medical Centre Burgemeester s'Jacobplein 51

NL-3015 CA, Rotterdam (The Netherlands)

E-Mail a.vanlaerhoven@erasmusmc.nl (c) 2018 The Author(s) Karger

Published by S. Karger AG, Basel Open access

This article is licensed under the Creative Commons AttributionNonCommercial-NoDerivatives 4.0 International License (CC BY NC-ND) (http://www.karger.com/Services/OpenAccessLicense) Usage and distribution for commercial purposes as well as any distribution of modified material requires written permission. 
disease severity for a median of 9 and 6 years, respectively, implies that these patients are unlikely to progress to higher stages. This strengthens the validity of the found progression rates.

Nonetheless, our results could be affected by recall bias. However, we argue that a prospective observational study may be difficult due to ethical and practical reasons.

In conclusion, patients with current Hurley III HS had a quicker and more aggressive disease course compared with patients with current Hurley II HS. This indicates that a relatively rapid disease progression from Hurley I to Hurley II is a predictive factor to develop Hurley III HS, and therefore a sign of a poor prognosis. These findings stress the relevance of early diagnosis and adequate treatment and follow-up in early stages of HS.

Key Message

Hurley III hidradenitis suppurativa has an aggressive disease course.

\section{Disclosure Statement}

The authors declare no conflicts of interest to declare.

\section{References}

1 Zouboulis CC, Desai N, Emtestam L, Hunger R, Ioannides D, Juhász I, Lapins J, Matusiak L, Prens E, Revuz J: European S1 guideline for the treatment of hidradenitis suppurativa/acne inversa. J Eur Acad Dermatol Venereol 2015;29:619-644.

2 Schrader AM, Deckers IE, van der Zee HH, Boer J, Prens EP: Hidradenitis suppurativa: a retrospective study of 846 Dutch patients to identify factors associated with disease severity. J Am Acad Dermatol 2014;71: 460-467.

3 Hurley H: Axillary hyperhidrosis, apocrine bromhidrosis, hidradenitis suppurativa, and familial benign pemphigus: surgical approach; in Roenigk RK, Roenigk HH (eds): Dermatologic Surgery. New York, Marcel Dekker, 1989, pp 729-739.

4 Deckers I, Mihajlović D, Prens E, Boer J: Hidradenitis suppurativa: a pilot study to determine the capability of patients to self-assess their Hurley stage. Br J Dermatol 2015;172:1418-1419.

5 Kromann CB, Deckers IE, Esmann S, Boer J, Prens EP, Jemec GB: Risk factors, clinical course and long-term prognosis in hidradenitis suppurativa: a cross-sectional study. Br J Dermatol 2014;171:819-824.

6 Von der Werth J, Williams H: The natural history of hidradenitis suppurativa. J Eur Acad Dermatol Venereol 2000;14:389-392. 